\title{
VARIACIÓN GENÉTICA DE LA RESISTENCIA A Puccinia triticina E. EN TRIGOS DUROS DE OAXACA, MÉXICO
}

\author{
GENETIC VARIATION OF RESISTANCE AGAINST Puccinia triticina E. IN DURUM WHEATS FROM \\ OAXACA, MÉXICO
}

\author{
Julio Huerta Espino ${ }^{1 *}$, Ma. Elsa Rodríguez Contreras², Ma. Florencia Rodríguez García ${ }^{1}$, H. Eduardo \\ Villaseñor Mir ${ }^{1}$, S. Gerardo Leyva Mir $^{2}$ y Eduardo Espitia Rangel ${ }^{1}$
}

\begin{abstract}
${ }^{1}$ Programa de Trigo Campo Experimental Valle de México, Instituto Nacional de Investigaciones Forestales Agrícolas y Pecuarias (INIFAP). Apdo. Postal 10. 56250, Coatlinchan, Texcoco, Estado de México. Tels: 01(595) 9212627, 9212715 Ext. 163. ${ }^{2}$ Departamento de Parasitologia, Universidad Autónoma Chapingo. 56230, Chapingo, Texcoco, Estado de México.
\end{abstract}

* Autor para correspondencia (j.huerta@cgiar.org)

\section{RESUMEN}

Colectas de trigos duros (Triticum turgidum var durum) proveniente del Estado de Oaxaca y denominados 'ventureros', fueron resistentes a la raza BBG/BN de roya de la hoja (Puccinia triticina E.) que preferentemente ataca a trigos duros. Se cruzaron cuatro de estas colectas con los genotipos susceptibles 'Altar C84' y 'Atil C2001', con el propósito de determinar en su progenie la genética de tal resistencia. Las colectas resultaron genéticamente heterogéneas; en consecuencia, la respuesta a la resistencia dependió de la planta utilizada como progenitor. Así, en las colectas 'CWI52201' y 'CWI52271' se encontraron dos casos de resistencia: la conferida por un gen dominante y la de dos genes epistáticos recesivos duplicados; en esta última y en la mayoría de las cruzas la resistencia la otorgaron los dos genes en forma dominante, $y$ en las menos fueron dos genes recesivos duplicados. El mismo resultado de la herencia de la resistencia se encontró para las colectas 'CWI52274' 'CWI52345', excepto la conferida por dos genes duplicados recesivos.

Palabras clave: Puccinia triticina, resistencia genética, Triticum durum, trigos criollos ventureros.

\section{SUMMARY}

Land races of durum wheat (Triticum turgidum var durum), called 'ventureros', collected in the Oaxaca state of México, showed resistance to durum leaf rust (Puccinia triticina $\mathbf{E}$.) race $\mathbf{B B G} / \mathbf{B N}$ that affects mainly durum wheats. Four of these collections were crossed to the susceptible durum wheat cultivars 'Altar C84' and 'Atil C2001', in order to determine the genetics of the resistance to leaf rust in their offspring. The collections resulted genetically heterogeneous. Consequently, their response to resistance depended on the plant used as parent. In the collections 'CWI52201' and 'CWI52271' two cases of resistance were found: one conferred by a dominant gene and one conferred by two duplicated epistatic recessive genes; in the last one and in most crosses the resistance was conferred by two dominant genes; in the rest of the crosses resistances was due to two duplicated recessive genes. The same result regarding inheritance of resistance was found in collections
'CWI52274' and 'CWI52345', except that conferred by two duplicate recessive genes.

Index words: Puccinia triticina, genetic resistance, Triticum durum, 'ventureros' wheat landraces.

\section{INTRODUCCIÓN}

En México el trigo duro o cristalino Triticum durum es importante en el Noroeste, donde es cultivado en condiciones de riego, específicamente en los Valles del Yaqui y del Mayo, en el Estado de Sonora, y en los Valles del Carrizo y del Fuerte en el Estado de Sinaloa (Singh et al., 2004). En esta región se siembran durante el ciclo otoño-invierno (O-I) cerca de 250000 ha. Por más de 30 años en que fue cultivado en pequeña escala el trigo duro en el Noroeste de México, las variedades mostraron inmunidad a la roya de la hoja (Puccinia triticina E.); sin embargo, cuando la superficie se incrementó se propiciaron condiciones para que en el ciclo O-I 2000-2001, una raza nueva del patógeno, denominada $\mathrm{BBG} / \mathrm{BN}$, rompiera la resistencia de la variedad 'Altar C84'. Esta raza ha causando pérdidas de hasta 320 millones de pesos (Singh et al., 2004). Esta raza fue detectada por primera vez en el Noroeste de México pero ya está presente en casi todas las zonas trigueras del país, en donde se descubrió que más de $90 \%$ de la variabilidad genética disponible en los trigos duros en México es susceptible a la enfermedad (Singh $e t$ al., 2004).

En roya de la hoja existe una marcada diferencia entre las poblaciones del patógeno que atacan a trigos harineros (Triticum aestivum L.) (Ali et al., 1994; Singh, 1991; 
Singh y Dubin, 1997), respecto a las que atacan a los trigos duros (Huerta-Espino y Roelfs, 1989; Ali et al., 1994) y triticale (Cecale Cereale L.) (Singh, 1991). La generación de variedades resistentes en los inicios del mejoramiento en México, fue encaminada a usar genes de resistencia específicos que facilitaran la selección al cruzar resistente $\mathrm{x}$ susceptible o resistente $\mathrm{x}$ resistente, $\mathrm{y}$ se heredaban en forma simple (Huerta-Espino y Singh, 2000). Las variedades, por lo general, poseen un gen dominante de resistencia que produce una respuesta de hipersensibilidad. Esta resistencia puede durar muy poco tiempo, dado que se pierde cuando el patógeno evoluciona hacia nuevas formas de virulencia. En México la duración promedio de este tipo de resistencia es de 3 a 5 años (Singh y Dubin, 1997). En dos sintéticos hexaploides Aguilar et al. (1999) determinaron la presencia de un gen recesivo que otorga resistencia a la raza $\mathrm{TCB} / \mathrm{TD}$ de roya de la hoja, mientras que al cruzar trigos sintéticos hexaploides con las variedades susceptibles a roya de la hoja 'Morocco', 'Chinese Spring', 'Opata 85' y 'Sonora 64', Aguilar et al. (2000) demostraron que la resistencia fue conferida por un gen dominante.

Al cruzar una variedad susceptible por una resistente, en su progenie es posible determinar tanto el tipo de acción génica como el número de genes que confieren la resistencia. Zhang y Knott (1990) estudiaron ocho cultivares de trigo duro resistentes a roya de la hoja de diversos orígenes; sus resultados mostraron que genes dominantes y recesivos o combinaciones de ellos confirieron resistencia en plántula. También observaron que todas las cruzas entre los progenitores resistentes segregaron plantas susceptibles, lo que indica que cada uno de los ocho cultivares poseen diferentes genes de resistencia.

En el caso en donde ambos genotipos homocigóticos recesivos producen fenotipos idénticos, su progenie se modifica a 9:7. Los genotipos aaB-, A-bb y aabb producen un sólo fenotipo que se expresa como plantas susceptibles. Cuando se presentan juntos ambos alelos dominantes se complementan uno con otro y producen un fenotipo 'AABB' resistente (Stanfield, 1983). Fitzgerald et al. (1957) reportaron la presencia de dos genes recesivos duplicados que confieren resistencia a la raza 65; estos genes fueron designados como $\operatorname{Lr} 7$ y $\operatorname{Lr} 8$.

Statler (1973) encontró que en la variedad de trigo cristalino 'Leeds' la resistencia a la raza 70-1 (Raza 1) de $P$. recondita fue condicionada por dos genes recesivos independientes, mientras que Ortiz et al. (1976) determinaron que un gen recesivo condiciona la resistencia a la raza 77 en los genotipos 'Stork' y 'Dwarf15-Cr', mientras que en la línea 'Crane' existen dos genes independientes. Rashid et al. (1976) estudiaron la herencia de la resistencia de roya de la hoja en la raza 70I (raza 1) en tres cultivares de trigo duro, 'Ramsey', 'D561' y 'D6733'; encontraron que dos genes recesivos duplicados condicionaron la resistencia en la variedad 'Ramsey', mientras que sólo hay un recesivo en las variedades 'D561' y 'D6733'.

La herencia de la resistencia en planta adulta en la raza 15 de roya de la hoja fue estudiada por Zhang y Knott (1993) en los cultivares duros 'Lloyd', 'Medora', 'Pelissier', 'Quilafen', 'Stewart 63' y 'Wakooma', los cuales habían mostrado tener genes de resistencia en plántula. Realizaron cruzas directas y recíprocas de cada cultivar con la línea susceptible 'RL6089'. Los resultados revelaron que los genes de resistencia en plántula fueron efectivos en planta adulta en evaluaciones en campo, y fue en la segregación de las progenies de $\mathrm{BC}_{1} \mathrm{~F}_{2}$ donde se encontró que 'Lloyd' posee un gen dominante y 'Pelissier' un gen recesivo; en ambos materiales dichos genes sólo se manifiestan en planta adulta.

Singh et al. (1993) hicieron cruzas de nueve trigos duros con el genotipo 'DW7276' susceptible a la raza $\mathrm{BBB} / \mathrm{BN}$, y encontraron que un gen parcialmente dominante confiere resistencia en plántula en las variedades 'Altar 84', 'Carcomun', 'Morus' y 'Totanos'. Este gen en forma individual no confiere un nivel aceptable de resistencia en planta adulta; sin embargo, interactúa de manera aditiva con otros genes de efecto aditivo, los que confieren resistencia en planta adulta a las variedades 'Mexicali 75', 'Yavaros 79', 'Diver', 'Kingfisher' y 'Somorguho'.

En la Mixteca alta del Estado de Oaxaca se cultivan los trigos ventureros, donde Legoria y Muñoz (1992) hicieron 65 colectas. Se supone que éstos fueron introducidos a Oaxaca durante la colonia y su origen puede ser la Península Ibérica (DeLacy et al., 2000). Su cultivo es predominantemente en suelos volcánicos y su estación de crecimiento abarca los meses de octubre a abril, para aprovechar las últimas lluvias de verano, y de ahí su nombre de trigos ventureros. Estos trigos constituyen cultivares que los productores han seleccionado a través del tiempo y que poseen mecanismos de resistencia a sequía (Legaria y Muñoz, 1992). DeLacy et al. (2000) obtuvieron más de 10000 colectas de éstos, en alrededor de 219 sitios.

Debido a la importancia económica que representa el daño de la roya de la hoja en la producción nacional de trigos duros, y a la necesidad de identificar nuevas fuentes de resistencia, el objetivo del presente estudio fue determinar la herencia de la resistencia en plántula a la 
roya de la hoja en trigos duros ventureros colectados en la región de la Mixteca Oaxaqueña.

\section{MATERIALES Y MÉTODOS}

Para el presente estudio se compararon cuatro trigos criollos ventureros de un grupo de 330 genotipos colectados por el Centro Internacional de Mejoramiento de Maíz y Trigo (CIMMYT) y por el Instituto Nacional de Investigaciones Agrícolas y Pecuarias (INIFAP) durante 1990, bajo un proyecto apoyado por la Comisión Nacional de Biodiversidad (CONABIO); estos trigos se caracterizan por su resistencia a la raza BBG/BN, de roya de la hoja en plántula y en planta adulta.

Para la inoculación de plantas se utilizó la raza BBG/BN, cuya fórmula de avirulencia/virulencia es: $L r 1$, $2 a, 2 b, 2 c, 3,3 b g, 3 k a, 912,13,14 a, 15,16,17,18,19$, $21,24,25,27+31,28,29,30,32,34,35,36,37 / 10$, $11,14 b, 20,23,33$ (Singh et al., 2004).

\section{Cruzas y obtención de progenies $\mathbf{F}_{2}$}

Se realizaron cruzas directas y recíprocas entre los progenitores susceptibles 'Altar C84' y 'Atil C2000' con los ventureros resistentes 'CWI52201', 'CWI52271', 'CWI52274' y 'CWI52345' (Cuadro 1). Se sembraron seis semillas de cada cruza en tubos de PVC de $10 \mathrm{~cm}$ de diámetro y de $50 \mathrm{~cm}$ de longitud, que se mantuvieron en condiciones de invernadero hasta la germinación en $\mathrm{F}_{2}$. Se colocaron dos semillas por tubo y durante el amacollamiento se aclareó a una planta por tubo. De esta manera se cosecharon tres plantas $F_{1}$ por cruza, las cuales se cultivaron por separado para su evaluación como progenies $F_{2}$ provenientes de una sola planta $F_{1}$.

Cuadro 1. Cruzas directas (D) y recíprocas (R) de colectas de trigos ventureros duros resistentes a la roya de la hoja, raza BBG/BN, con las variedades susceptible 'Altar C84' y 'Atil C2000', para determinar la herencia de la resistencia.

\begin{tabular}{lcccc}
\hline Progenitor & 'CWI52201' & 'CWI52271' & 'CWI52274' & 'CWI52345' \\
\hline 'Altar C84' & D, R & D, R & R & R \\
'Atil C2000' & D, R & D, R & D, R & D, R \\
\hline
\end{tabular}

\section{Evaluación de progenies $F_{2}$}

La semilla cosechada de cada planta $F_{1}$ de cada cruza directa y recíproca, se sembró en condiciones de invernadero en El Batán, Texcoco, Estado de México, para su evaluación en estado de plántula. Debido a que no se obtuvo igual número de semillas $\mathrm{F}_{2}$ de cada una de las plantas $F_{1}$ en estudio, el número de plántulas $F_{2}$ evaluadas varió para cada progenie, así como varió el número de progenies de cada cruza. Cuando no se observó variación entre las progenies de las plantas $\mathrm{F}_{1}$ de una misma cruza, se sumó el total de todas las plantas.

Siembra de materiales. La siembra se hizo en charolas de plástico de 20 × $30 \mathrm{~cm}$ con capacidad para 100 semillas (plántulas). Con una plancha de acero se formaron orificios de $1 \mathrm{~cm}$ de diámetro por $2 \mathrm{~cm}$ de profundidad, en suelo previamente desinfectado; luego se colocaron las semillas, una por cada hoyo; enseguida se cubrieron con suelo y se les proporcionó riego. Las charolas fueron mantenidas en el invernadero a una temperatura de $18{ }^{\circ} \mathrm{C}$ durante la noche y $20{ }^{\circ} \mathrm{C}$ durante el día. Las plántulas se fertilizaron con la fórmula $17 \mathrm{~N}-17 \mathrm{P}-17 \mathrm{~K}$ soluble en agua, aplicando $12.5 \mathrm{~mL}$ por charola.

Inoculación de plántulas. Cuando habían transcurrido 16 d después de la siembra, las plántulas fueron inoculadas artificialmente mediante aspersión de la hoja con una suspensión de urediniosporas en aceite mineral (Sotrol $170 \circledast$ ), cuya concentración de esporas fue de 2 a 3 $\mathrm{mg} \mathrm{mL}^{-1}$ de aceite (Herrera-Foessel et al., 2005). Una vez que las plantas se inocularon, se dejaron reposar por 20 min.; luego se colocaron por $16 \mathrm{~h}$ dentro de una cámara humidificadora a $100 \%$ de humedad relativa. Posteriormente, las charolas se trasladaron al invernadero donde se mantuvieron entre 20 a $24{ }^{\circ} \mathrm{C}$, hasta la aparición de los signos de la enfermedad.

Evaluación. Las lecturas se llevaron a cabo 12 d después de la inoculación, una vez que los signos fueron visibles. La evaluación de las plántulas se hizo de manera visual, de acuerdo con el tipo de infección producida por el patógeno en la hoja inoculada, mediante la escala de Roelfs et al. (1992), como se muestra en el Cuadro 2. Posteriormente se contabilizó el número de plántulas resistentes, el número de plántulas intermedias o segregantes, y el número de plántulas susceptibles. Para los análisis de datos sólo se consideraron dos grupos de fenotipos: susceptibles ( 3 a $3^{+}$ó 4 ), y resistentes que involucraron plantas con reacción intermedia 0 segregantes $(0,1$ y 2$)$. 
Cuadro 2. Respuestas del hospedante y descripciones de las reacciones de infección usadas para evaluar roya de la hoja, Puccinia triticina E. (Modificado de Roelfs et al., 1992).

\begin{tabular}{|c|c|c|}
\hline $\begin{array}{l}\text { Respuesta del } \\
\text { hospedante (clase) }\end{array}$ & $\begin{array}{l}\text { Reacción de } \\
\text { infección }^{\dagger}\end{array}$ & Síntomas de la enfermedad \\
\hline Inmune & 0 & Ningún uredinio presente. \\
\hline Casi inmune & ; & $\begin{array}{l}\text { No uredinios, pecas cloróticas o necróticas presentes que indican } \\
\text { hipersensibilidad. }\end{array}$ \\
\hline Muy resistente & 1 & Uredinios pequeños rodeados por necrosis. \\
\hline Moderadamente resistente & 2 & $\begin{array}{l}\text { Uredinios pequeños o de tamaño mediano a menudo rodeados por clorosis } \\
\text { o necrosis; puede haber una isla verde rodeada por un borde clorótico o } \\
\text { necrótico. }\end{array}$ \\
\hline Heterogénea & $\mathrm{X}$ & $\begin{array}{l}\text { Uredinios de tamaño variable (todos los tipos de infeccion en la misma } \\
\text { hoja) }\end{array}$ \\
\hline Moderadamente susceptible & 3 & Uredinios de tamaño mediano que está asociado con cierta clorosis. \\
\hline Susceptible & 4 & Uredinios grandes sin clorosis. \\
\hline
\end{tabular}

Análisis de datos. Mediante la frecuencia de plántulas susceptibles y resistentes con la prueba de Ji-cuadrada $\left(\chi^{2}\right)$ se determinó la bondad del ajuste de los datos obtenidos con los esperados en cada cruza (Gardner et al., 1998). Cuando los datos obtenidos de progenies de plantas individuales de una misma cruza diferían en las proporciones observadas, se mantuvieron separadas; cuando no diferían, se analizaron en forma conjunta.

\section{RESULTADOS Y DISCUSIÓN}

Los resultados revelaron que en las cuatro cruzas (Cuadros 3, 4, 5 y 6) hubo progenies $F_{2}$, cuya segregación se ajustó a la relación fenotípica 9 resistentes por 7 susceptibles, lo que indica la presencia de epistasis de dos genes recesivos duplicados, donde la combinación dominante-dominante es la que otorga la resistencia. En tres cruzas se identificaron progenies que también segregaron en epistasis de genes recesivos duplicados, con 7 resistentes por 9 susceptibles; pero en estos casos la combinación dominanate-dominante fue la susceptible, mientras que las combinaciones dominante-recesivas, recesivo-dominante $\mathrm{y}$ doble recesivas fueron las resistentes. En los mismos cuadros se muestran progenies cuya segregación observada se ajustó a la relación de 3 resistentes por 1 susceptible, lo que indica que es un gen dominante el que otorga la resistencia. Estos resultados permiten inferir que dentro de cada una de las cuatro colectas de trigos cristalinos ventureros, aunque fenotípicamente homogéneas entre sí, hay variabilidad genética en su resistencia a la roya de la hoja.
En las progenies de las cruzas directas y recíprocas del progenitor 'CWI52201' con la variedad 'Altar C84', se encontraron los dos casos de herencia de la resistencia detectados: la de un gen dominante y la de epistasis de dos genes recesivos duplicados en su forma de acción dominante y también recesiva. En la cruza directa y recíproca del mismo progenitor 'CWI52201' con la variedad 'Atil C2001', la herencia de la resistencia fue de tipo epistática en los dos casos (Cuadro 3).

Para el caso de las cruzas directa y recíproca del progenitor 'CWI52271' con la variedad 'Altar C84', la resistencia fue conferida por un gen dominante (Cuadro 4), pero no así cuando se cruzó con la variedad 'Atil C2001', donde la resistencia fue resultado de las tres situaciones de acción génica antes descritas.

En la cruza de la colecta 'CWI52274' se detectó variación en las progenies de las diferentes plantas $\mathrm{F}_{1}$ analizadas; por un lado se identificó la acción de un gen dominante en tres plantas de la cruza con 'Altar C84' y en una planta de la cruza con 'Atil C2001'. En la cruza tanto con 'Altar C84' como con 'Atil C2001' también se identificó la acción de dos genes complementarios dominantes (Cuadro 5). En la cruza de 'CWI52345' con 'Altar C84' se detectó la presencia de un gen dominante, y en la progenie de la cruza recíproca se encontraron dos genes complementarios dominantes, mientras que en la progenie de plantas provenientes de cruzas directas y recíprocas con la variedad 'Atil C2001' sólo se encontró la presencia de dos genes complementarios dominantes (Cuadro 6). 
Cuadro 3. Número de plantas totales (TT), resistentes (R) y susceptibles (S) observadas (O) y esperadas (E), relaciones fenotípicas, valor de $\chi^{2}$ y su probabilidad (Prob.), en las cruzas directas y recíprocas de la colecta 'CWI52201' con los progenitores susceptibles 'Altar C84' y 'Atil C2000.'



${ }^{\dagger}=$ cuando no se específica el número de planta $\mathrm{F}_{1}$, los datos son el resultado de dos o más plantas $\mathrm{F}_{1}$, REL $=$ relación fenotípica.

Cuadro 4. Número de plantas totales (TT), resistentes (R) y susceptibles (S) observadas (O) y esperadas (E), relaciones fenotípicas, valor de $\chi^{2}$ y su probabilidad (Prob.), en las cruzas directas y recíprocas de la colecta 'CWI52271' con los progenitores susceptibles 'Altar C84' y 'Atil C2000'.

\begin{tabular}{|c|c|c|c|c|c|c|c|c|c|}
\hline Cruza $^{\dagger}$ & & \multicolumn{5}{|c|}{ Número de plantas } & REL & $\chi^{2}$ & Prob. \\
\hline & C. recíproca & & & & & & & & \\
\hline Atil x CWI52271 TCD02007-2F1 & & 109 & 78 & 81.8 & 31 & 27.3 & $3: 1$ & 0.688 & $0.50-0.20$ \\
\hline & C. recíproca & & & & & & & & \\
\hline CWI52271 x Atil TCD02008-2F1 & & 69 & 51 & 51.8 & 18 & 17.3 & $3: 1$ & 0.043 & $0.95-0.80$ \\
\hline CWI52271 x Atil TCD02008-1F1 & & 42 & 25 & 23.6 & 17 & 18.4 & $9: 7$ & 0.183 & $0.80-0.50$ \\
\hline CWI52271 x Atil TCD02008-3F1 & & 49 & 23 & 21.4 & 26 & 27.6 & $7: 9$ & 0.202 & $0.80-0.50$ \\
\hline
\end{tabular}

${ }^{\dagger}=$ cuando no se específica el número de planta $\mathrm{F}_{1}$, los datos son el resultado de dos o más plantas $\mathrm{F}_{1}$, REL = relación fenotípica.

Cuadro 5. Número de plantas totales (TT), resistentes (R) y susceptibles (S) observadas (O) y esperadas (E), relaciones fenotípicas, valor de $\chi^{2}$ y su probabilidad (Prob.), en las cruzas directas y recíprocas de la colecta 'CWI52274' con los progenitores susceptibles 'Altar C84' y 'Atil C2000'.

\begin{tabular}{|c|c|c|c|c|c|c|c|c|}
\hline Cruza $^{\dagger}$ & \multicolumn{5}{|c|}{ Número de plantas } & REL & $\chi^{2}$ & Prob. \\
\hline CWI52274 x Altar TCD02009-2F1 & 46 & 25 & 25.9 & 21 & 20.1 & $9: 7$ & 0.068 & $0.80-0.50$ \\
\hline \multicolumn{9}{|c|}{ C. recíproca } \\
\hline CWI52274 x Atil TCD02011 & 268 & 166 & 151 & 102 & 117 & $9: 7$ & 3.52 & $0.10-0.05$ \\
\hline
\end{tabular}

${ }^{\dagger}=$ cuando no se específica el número de planta $\mathrm{F}_{1}$, los datos son el resultado de dos o más plantas $\mathrm{F}_{1}$, REL $=$ relación fenotípica

Cuadro 6. Número de plantas totales (TT), resistentes (R) y susceptibles (S) observadas (O) y esperadas (E), relaciones fenotípicas, valor de $\chi^{2}$ y su probabilidad (Prob.), en las cruzas directas y recíprocas de la colecta 'CWI52345' con los progenitores susceptibles 'Altar C84' y Atil C2000.'

\begin{tabular}{|c|c|c|c|c|c|c|c|c|c|}
\hline Cruza $^{\dagger}$ & & \multicolumn{5}{|c|}{ Número de plantas } & REL & $\chi^{2}$ & Prob. \\
\hline CWI52345 x Altar TCD02012 & & 247 & 183 & 185 & 64 & 61.8 & $3: 1$ & 0.109 & $0.80-0.50$ \\
\hline CWI52345 x Altar TCD02012 & & 149 & 88 & 83.8 & 61 & 65.2 & $9: 7$ & 0.478 & $0.80-0.50$ \\
\hline & C. recíproca & & & & & & & & \\
\hline CWI52345 x Atil TCD02013 & & 182 & 115 & 102 & 67 & 79.6 & $9: 7$ & 3.559 & $0.20-0.05$ \\
\hline
\end{tabular}

${ }^{\dagger}=$ los datos son el resultado de dos o más plantas $\mathrm{F}_{1}, \mathrm{REL}=$ relación fenotípica. 
Los estudios de la herencia de la resistencia a roya de la hoja en trigo duro ha sido limitada, primero por la falta de variación en las poblaciones de roya de la hoja que preferentemente atacan trigos duros, segundo por el desconocimiento de un genotipo susceptible de trigo duro y tercero debido a la poca importancia que esta enfermedad tenía en trigos duros, ya que la variedad 'Altar C84' había permanecido resistente en México por más de 17 años. Ante las limitaciones señaladas y la presencia de variedades resistentes en trigos duros, varios investigadores han tomado como modelo para sus estudios de la herencia de la resistencia, a la roya de la hoja que ataca preferentemente al trigo harinero; en la mayoría de casos los resultados revelaron que la herencia de la resistencia es predominantemente cualitativa, otorgada por genes simples o acaso dos pares de genes independientes o epistáticos. Así, por ejemplo, Ortiz et al. (1976) encontraron en la variedad 'Crane' la resistencia está condicionada por dos genes recesivos independientes, mientras que en 'Cocorit 71 ' se detectó un gen con dominancia incompleta. Por su parte, Zhang y Knott (1990) reportaron la posible presencia de un gen dominante (Lr17) en la variedad 'Quilafen'.

La acción de genes complementarios dominantes (AABB) encontrada en las colectas de trigos ventureros y que les otorgan resistencia a la roya de la hoja, también se ha detectado en la variedad 'Jupare C2001' (HerreraFoessel et al., 2005); sin embargo, según Huerta-Espino et al. (2009), los genes dominantes presentes en 'Jupare C2001' ya no son efectivos en las razas del patógeno identificadas en el 2008. Lo más probable es que este par de genes complementarios sean $L r 27+31$, previamente identificados en trigos harineros ( Sing y McIntosh, 1984a y 1984b). Existe una alta probabilidad de que este mismo par de genes esté presente en la variedad 'Banamichi C2004', pues también fue susceptible cuando la raza BBG/BN evolucionó en virulencia para vencer la resistencia de los genes $L r 27+31$ en la raza BBG/BP (Huerta-Espino et al., 2009).

La presencia de dos genes recesivos complementarios (aabb) fueron reportados en la variedad 'Ramsey' (Rashid et al., 1976). Por definición, los genes complementarios se refieren a la acción conjunta de dos genes dominantes independientes. Por tanto, para que se exprese la resistencia ambos alelos deben estar presentes en forma de homocigótica (AABB). El primer caso de este tipo de resistencia fue documentado por Baker (1966), quién determinó la presencia de dos genes dominantes complementarios que condicionan la resistencia en la variedad 'Bond' de avena (Avena sativa L.), para roya de la corona (Puccinia coronata).
Posteriormente, Singh y McIntosh (1984a) determinaron la presencia de dos genes complementarios en la variedad 'Gatcher', que confieren resistencia a $P$. triticina. Singh y McIntosh (1984b) designaron a estos mismos genes como $L r 27$ y $L r 31$ y los ubicaron en los cromosomas $4 \mathrm{AB}$ y $3 \mathrm{BS}$, respectivamente; según estos autores ambos genes deben estar presentes para la expresión de la resistencia en trigos como CS ('Hope' 3B) y 'Gatcher'. Con base en estos resultados, el par de genes complementarios en los trigos ventureros que son resistentes a la raza $\mathrm{BBG} / \mathrm{BP}$, deben ser entonces diferentes al par formado por $L r 27+L r 31$, que ya no muestran resistencia a la misma raza (Huerta-Espino et al., 2009).

Existe una serie de factores que puede producir sesgos en la evaluación de plántulas resistentes y susceptibles, y de ahí la importancia de evaluar progenies que provengan de plantas individuales $F_{1}$, y así contabilizar el total para confirmar resultados. Las frecuencias de plantas resistentes y susceptibles o de familias resistentes y susceptibles, en la proporción 9:7, no permiten distinguir la presencia de un gen supresor para uno de los genes. Se ha encontrado que los genes supresores en el caso de la resistencia son específicos y generalmente se encuentran en el cromosoma homólogo del genoma, aparentemente en la misma posición (Nelson et al., 1997; Villarreal et al., 1992; Kema y Lange, 1992). Si las frecuencias observadas son resultado del gen supresor Lr23, éste debería estar presente en el progenitor susceptible (Nelson et al., 1997; Aguilar et al., 1999).

Los resultados obtenidos de segregaciones de plantas $\mathrm{F}_{2}$ podrían corroborarse mediante estudios en familias $\mathrm{F}_{3}$, con el fin de fortalecer los resultados encontrados. Es importante considerar que, dado el origen de los trigos ventureros los cuales no han estado sujetos a mejoramiento genético, no era de esperarse que se determinaran relaciones fenotípicas que involucraran a más de dos genes. El gen dominante encontrado en la segregación de las cruzas entre los trigos ventureros con los progenitores susceptibles 'Altar C84' y 'Atil C2001', puede ser el gen $L r 1$, mientras que los genes recesivos duplicados podrían ser genes no reportados aún. El uso de la resistencia mostrada por estos trigos ventureros en un programa de mejoramiento genético para resistencia a la roya de la hoja, debe ser en combinación con otros genes, que incluyan al gen presente en 'Altar C84' y sus derivados, para asegurar su efectividad por un tiempo más largo.

Estas fuentes de resistencia, por su origen deben ser diferentes a las antes identificadas, por lo que deben combinarse con otros genes en un programa de 
mejoramiento genético a corto y mediano plazo en las nuevas variedades de trigos cristalinos, lo que permitiría controlar genéticamente a la roya de la hoja.

\section{CONCLUSIONES}

Los trigos ventureros no son genotipos genéticamente homocigotos-homogéneos para la resistencia a la raza BBG/BN de roya de la hoja, y su resistencia es de herencia simple condicionada por uno o dos pares de genes. Según la progenie $\mathrm{F}_{2}$ evaluada, la resistencia a la roya de la hoja en los trigos 'CWI52201' y 'CWI52271' es conferida por la presencia de un gen dominante $(3: 1)$, dos genes complementarios dominantes (9:7), o dos genes recesivos duplicados (7:9); mientras que en las colectas 'CWI52274' y 'CWI52345' la resistencia es determinada por un gen dominante y dos genes complementarios dominantes.

\section{AGRADECIMIENTOS}

Al Proyecto Fiscal de trigo del INIFAP, Número PRECI 2056029a.

\section{BIBLIOGRAFÍA}

Ali I, A P Roelfs, J Huerta-Espino (1994) Inheritance of leaf rust resistance in wheat cultivars Morocco and Little club. Plant Dis. 78:383-384.

Aguilar R V H, R P Singh, J D Molina (1999) Genética de la resistencia a la roya de la hoja de cuatro trigos sintéticos hexaploides. Rev. Fitotec. Mex. 22:215-226.

Aguilar R V H, R P Singh, J D Molina, J Huerta-Espino (2000) Herencia de la resistencia a la roya de la hoja en cuatro trigos sintéticos hexaploides. Agrociencia 34: 235-245.

Baker E P (1966) Isolation of complementary genes conditioning crown rust resistance in the oat variety Bond. Euphytica 15:313-318.

DeLacy I H, B Skovmand, J Huerta-Espino (2000) Characterization of Mexican wheat landraces using agronomically useful atributes. Genet. Resour. Crop Evol. 47:591-602.

Fitzgerald P J, R M Caldwell, O E Nelson Jr (1957) Inheritance of resistance to certain races of leaf rust of wheat. Agron. J. 49:539-543.

Gardner E J, M J Simons, D P Snustad (1998) Principios de Genética. Editorial Limusa Wiley. México, D. F. 149 p.

Herrera-Foessel S A, R P Singh, J Huerta-Espino, J Yuen, A Djurle (2005) New genes for leaf rust resistance in CIMMYT durum wheats. Plant Dis. 89:809-814.

Huerta-Espino J, A P Roelfs (1989) Physiological specialization on leaf rust on durum wheat. Phytopathology 79:1218.

Huerta-Espino J, R P Singh (2000) Las royas del trigo. In: El Trigo de Temporal en México. Villaseñor M, E Espitia R (eds) SAGAR, INIFAP, CIR-CENTRO CEVAMEX. México. pp: 231-251.

Huerta-Espino J, R P Singh, S A Herrera-Foessel, B Pérez-López, P Figueroa-López (2009) First detection of virulence in Puccinia triticina to resistance genes $L r 27+L r 31$ present in durum wheat in Mexico. Plant Dis. 93:110.

Kema G H J, W Lange (1992) Race-specific supression of resistance to yellow rust in synthetic hexaploids of wheat. Vortr. Pflanzenzuchtg. 24:206.
Legaria S J P, A Muñoz O (1992) Interacción de variedades de trigo con ambientes críticos de la Mixteca Alta Oaxaqueña. Fitotecnia 15:40-50.

Nelson J C, R P Singh, J E Autrique, M E Sorrells (1997) Mapping genes conferring and suppressing leaf rust resistance in wheat. Crop Sci. 37:1928-1936.

Ortiz F G, V A Rodríguez, M A Quiñonez (1976) Herencia de la resistencia en trigos duros (Triticum durum Desf.) a Puccinia graminis f. sp. tritici Erickss. y Henn. y Puccinia recondita f. sp. tritici Erickss. y Henn. Agrociencia 25:89-99.

Rashid G, J S Quick, G D Statler (1976) Inheritance of leaf rust resistance in three durum wheats. Crop Sci. 16:294-296.

Roelfs A P, R P Singh, E Saari (1992) Las Royas del Trigo: Conceptos y Métodos para el Manejo de esas Enfermedades. México, D. F. CIMMYT. 81 p.

Singh R P (1991) Pathogenicity variations of Puccinia recondita f. sp. tritici and $P$. graminis f. sp. tritici. in wheat-growing areas of Mexico during 1988 and 1989. Plant Dis. 75:790-794.

Singh R P, E Bechere, O Abdalla (1993) Genetic analysis of resistance to leaf rust in nine durum wheats. Plant Dis. 77:460-463.

Singh R P, H J Dubin (1997) Sustainable control of wheat diseases Mexico. In: Memorias del Primer Simposio Internacional de Trigo. 7-9 de abril de 1997, Cd. Obregón, Sonora. pp:93-102.

Singh R P, J Huerta-Espino, P Figueroa L, W Pfeiffer (2004) Occurrence and impact of a new leaf rust race on durum wheat in the Nothwestern Mexico from 2001-2003. Plant Dis. 88:703-708.

Singh R P, R A McIntosh (1984a) Complementary genes for reaction to Puccinia recondita tritici in Triticum aestivum. I. Genetic and linkage studies. Can. J. Genet. Cytol. 26:723-735.

Singh R P, R A McIntosh (1984b) Complementary genes for reaction to Puccinia recondita tritici in Triticum aestivum. II Cytogenetic studies. Can. J. Genet. Cytol. 26:736-742.

Stanfield W D (1983) Shaum's Outline Series, Theory and Problems of Genetics. 2nd ed. McGraw, Inc. U.S.A. 574 p.

Statler G D (1973) Inheritance of leaf rust resistance in Leeds durum wheat. Crop Sci. 13:116-117.

Villareal R L, R P Singh, A Kazi-Mujeeb (1992) Expression of resistance to Pucccinia recondita f. sp. tritici in synthetic hexaploide wheats. Vortr. Pflanzenzuechtg. 24:253-255.

Zhang H, D R Knott (1990) Inheritance of leaf rust resistance in durum wheat. Crop Sci. 30:1218-1222.

Zhang H, D R Knott (1993) Inheritance of adult plant resistance to leaf rust in six durum wheat cultivars. Crop Sci. 33:694-69. 